\title{
Editorial
}

\section{A new deal for the Monaldi Archives for Chest Disease}

This issue marks a change in the Editorial Board of Monaldi Archives for Chest Disease. We would like to take this opportunity to impart some news on the current status of the journal. Our submissions are increasing, citations to our papers are rising, and recognition of the journal is broadening.

Overall, 2016 has been a good year for the journal. Several changes are being made and several more are coming soon.

Yet, focussing on the results achieved only is not our main goal, hence we now direct our efforts toward reaching an even greater impact.

During the year, we have worked on several changes: as of May 2017, the new Editorial Board will be announced on the journal's web site, www.monaldi-archives.org. Many reputable individuals were invited and have accepted to become members of the new Board.

Readers should note that we sought to enlist a board that would represent different areas of Cardiovascular and Pneumology, as well as geographic diversity.

As in the past, the members of the board will also serve as reviewers and Associate Editors (AE). The role as AE is particularly important, since all submissions in which there is an author with whom the editor has published are assigned to the AE to ensure an impartial process.

Therefore, the people on the Editorial Board are extremely important as they will do the majority of the reviews, and this will hopefully guarantee the quality of our reviews. The journal is also working hard on speeding up the review process and reducing the time from submission to decision.
We know that our future success still depends on the wisdom and contributions of the members of our founding Editorial Board. We consider them emeriti, we thank them, and we are hopeful that they will be able to provide mentorship to the journal.

We would also like to take this opportunity to thank all those who served the Journal in the past, either in the old Editorial Board or in the International Advisory Board. When the new Board was considered, we searched for new people and are delighted to say that it now includes many young researchers.

The Board has also been revitalised and will play an important role in the future development of the journal. We welcome them as part of our quest to make a positive difference.

As you all will notice, from April 2017 the journal has a new front cover. The new cover is a strong sign that new winds are blowing. The journal also has a new website, and one important project for 2017 is to improve it even more and to use it as a link to the ICS MAUGERI Society, thus increasing the communication with the readers.

Together, all of us - Editors, Associate Editors, Reviewers and Authors - will co-operate to make Monaldi Archives for Chest Disease a leading journal in the cardiopulmonary field in the future. We are confident that 2017 will be an even better year.

We sincerely look forward to working with all of you in the future.

\section{The Editors-in-Chief}

Antonio Spanevello

Bruno Balbi

Francesco Fattirolli

Furio Colivicchi
Corresponding author: Antonio Spanevello, Dipartimento di Medicina e Riabilitazione Cardio Respiratoria, Istituti Clinici Scientifici Maugeri, IRCCS Tradate, Via Roncaccio, 16, 21049 Tradate (VA), Italy.

E-mail: antonio.spanevello@icsmaugeri.it

Received for publication: 9 May 2017

Accepted for publication: 15 May 2017

(C) Copyright A. Spanevello et al., 2017

Tipografia PI-ME Editrice, Italy

Monaldi Archives for Chest Disease 2017; 87:837

doi: 10.4081/monaldi.2017.837

This article is distributed under the terms of the Creative Commons Attribution Noncommercial License (by-nc 4.0) which permits any noncommercial use, distribution, and reproduction in any medium, provided the original author(s) and source are credited. 